\title{
Corrigendum: Overlap Syndrome Involving Systemic Lupus Erythematosus and Autoimmune Hepatitis in Children: A Case Report and Literature Review
}

\author{
Wan-Tz Lai ${ }^{1 \dagger}$, Wan-Hua Cho ${ }^{2 \dagger}$, Hock-Liew Eng ${ }^{3}$, Ming-Hui Kuo ${ }^{1}$ and Fu-Chen Huang ${ }^{1 *}$ \\ ${ }^{1}$ Department of Pediatrics, Kaohsiung Chang Gung Memorial Hospital, Chang Gung University College of Medicine, \\ Kaohsiung, Taiwan, ${ }^{2}$ Department of Ophthalmology, Kaohsiung Chang Gung Memorial Hospital, Chang Gung University \\ College of Medicine, Kaohsiung, Taiwan, ${ }^{3}$ Department of Anatomic Pathology, Kaohsiung Chang Gung Memorial Hospital, \\ Chang Gung University College of Medicine, Kaohsiung, Taiwan
}

\section{OPEN ACCESS}

Approved by:

Frontiers Editorial Office, Frontiers Media SA, Switzerland

*Correspondence: Fu-Chen Huang huang817@cgmh.org.tw

tThese authors have contributed equally to this work

Specialty section: This article was submitted to Pediatric Gastroenterology, Hepatology and Nutrition, a section of the journal

Frontiers in Pediatrics

Received: 10 December 2019 Accepted: 11 December 2019

Published: 24 January 2020

Citation:

Lai W-T, Cho W-H, Eng H-L, Kuo M-H and Huang F-C (2020) Corrigendum:

Overlap Syndrome Involving Systemic Lupus Erythematosus and Autoimmune Hepatitis in Children: A Case Report and Literature Review. Front. Pediatr. 7:541. doi: 10.3389/fped.2019.00541
Keywords: overlap syndrome, childhood, systemic lupus erythematosus, autoimmune hepatitis, jaundice

\section{A Corrigendum on}

Overlap Syndrome Involving Systemic Lupus Erythematosus and Autoimmune Hepatitis in Children: A Case Report and Literature Review

by Lai, W.-T., Cho, W.-H., Eng, H.-L., Kuo, M.-H., and Huang, F.-C. (2019). Front. Pediatr. 7:310. doi: $10.3389 /$ fped.2019.00310

In the original article, there was an error. We neglected to include a statement and indication that the first two authors contributed equally to the work.

A correction has therefore been made to the Author Contributions statement and a symbol has been added in the author list.

"W-TL and W-HC drafted the initial manuscript, designed the study, interpreted the data, screened the literature, and approved the final manuscript for submission. W-TL and W-HC are equal contributors in this study. H-LE interpreted the specimen and provided recommendations for this manuscript. M-HK provided recommendations for this manuscript. F-CH conceptualized the study, reviewed and revised the manuscript, and approved the final manuscript for submission. All authors approved the final manuscript as submitted and agree to be accountable for all aspects of the work."

The authors apologize for this error and state that this does not change the scientific conclusions of the article in any way. The original article has been updated.

Copyright (0) 2020 Lai, Cho, Eng, Kuo and Huang. This is an open-access article distributed under the terms of the Creative Commons Attribution License (CC BY). The use, distribution or reproduction in other forums is permitted, provided the original author(s) and the copyright owner(s) are credited and that the original publication in this journal is cited, in accordance with accepted academic practice. No use, distribution or reproduction is permitted which does not comply with these terms. 